Portland State University

PDXScholar

2014

\title{
Mindfulness and Test Performance after Stereotype Activation: a Randomized Experiment
}

Charles J.Z. Daniel

Portland State University

Follow this and additional works at: https://pdxscholar.library.pdx.edu/honorstheses

Let us know how access to this document benefits you.

\section{Recommended Citation}

Daniel, Charles J.Z., "Mindfulness and Test Performance after Stereotype Activation: a Randomized Experiment" (2014). University Honors Theses. Paper 112.

https://doi.org/10.15760/honors.111

This Thesis is brought to you for free and open access. It has been accepted for inclusion in University Honors Theses by an authorized administrator of PDXScholar. Please contact us if we can make this document more accessible: pdxscholar@pdx.edu. 
Mindfulness and Test Performance after Stereotype Activation: A Randomized Experiment

by

Charles J.Z. Daniel

An undergraduate honors thesis submitted in partial fulfillment of the requirements for the degree of

Bachelor of Science

in

University Honors

and

Psychology

Thesis Adviser

Dr. Robert Roeser

Portland State University 
Acknowledgements: This research would not have been possible without the support of many wonderful people. Thank you to Dr. Robert Roeser for his continuous feedback, brilliant insights, and dedicated mentorship. Additional thanks to Dr. Todd Bodner, Dr. Kimberly Kahn, the Portland State University Honors College, and the McNair Scholars Program for their critical contributions to this project. 


\begin{abstract}
Although stereotype threat - pressure to avoid confirming or being judged based on a stereotype - has been found to affect performance on an array of tasks, few studies have examined ways to alleviate the threat after it has been activated. Previous research has demonstrated several outcomes of mindfulness exercises - increased emotional regulation, increased attentional regulation, change in perspective of self, and greater resources available to devote to learning - which parallel four potential mechanisms for stereotype threat: anxiety and SNS arousal, decreased working memory capacity, mindset, and effort. The present study tested the impact of two interventions - a 10-minute meditation practice and 10-minutes spent listening to relaxation music - on female math test performance in a stereotype threat situation. Participants were asked to indicate gender and the number of math courses they had taken in order to activate the "men are better than women at math" stereotype, then listened to music or meditation instructions for 10 minutes before filling taking a 20 -item test consisting of sample GRE questions. After the test, a 17 item survey was administered in order to evaluate potential mediating mechanisms. Results showed that (a) participants receiving the mindfulness intervention scored higher on the math test than participants who received no intervention after activation; and (b) participants receiving both the mindfulness and relaxation interventions were more likely than participants who received no intervention to report trying their hardest on the math test.
\end{abstract}

Keywords: stereotype threat, mindfulness 
Mindfulness and Test Performance after Stereotype Activation: A randomized control study Stereotype threat occurs when there is public knowledge of a stereotype about the performance of a specific group and a member of that stereotyped group either consciously or unconsciously feels pressure to avoid confirming or being judged based on the stereotype (Steele \& Aronson, 1995). This pressure has been found to impair performance on intellectual tasks when the stereotype is activated (Davis, Aronson, \& Salinas 2006). Research on stereotype threat suggests several mechanisms through which stereotype threat affects performance including anxiety (Bosson, Haymovitz, \& Pinel, 2004) and arousal of the sympathetic nervous system (SNS) (O’Brien \& Crandall, 2003), decreased working memory capacity (Beilock, Rydell, \& McConnell, 2007), and effort (Stone, 2002). Additionally, the success of researchers who have attempted to prevent stereotype threat by shaping participants view of intelligence before activation (e.g. Aronson, Fried, \& Good, 2002) suggests that this may be another potential mechanism.

Because of the recent discovery of these potential mechanisms, successful interventions which inoculate against stereotype threat are only beginning to be developed. Mindfulness exercises are a promising possibility because research suggests that contemplative practices are effective as an intervention in decreasing anxiety and dominant responses associated with SNS arousal (Hoffman, Sawyer, Witt, \& Oh, 2010; Brown, Goodman, \& Inzlicht, 2013), increasing working memory capacity (Jha, Stanley, Kiyonaga, Wong, \& Gelfland, 2010), changing perspective of self (Hölzel et al., 2011), and increasing resources available to devote to learning (thereby increasing effort) (Blair \& Diamond, 2008). The purpose of this study is to test the effectiveness of mindfulness exercises as an intervention for stereotype threat effects on math achievement among girls. 


\section{Stereotype threat}

When a stereotype exists about the way members of a certain group perform on a particular task, stigmatized group members may suffer decreased performance in situations where the stereotype is activated, regardless to whether or not the individual believes the stereotype or is aware that it has been activated (Steele \& Aronson, 1995). This effect, commonly referred to as stereotype threat, has been shown to affect the performance of negatively stereotyped groups including African Americans (Steele \& Aronson, 1995), Latinos (Aronson \& Salinas, 1997) members of low socioeconomic status (Croizet \& Claire, 1998), and gay men (Bosson, et al., 2004). Additionally, several studies have found that this phenomenon is extended to members of non-stigmatized groups when faced with a stereotype about the superior performance of another group. For example, Aronson et al. (1999) found that the existence of a positive stereotype about the math ability of Asians caused white men to perform worse when they believed their performance would be compared to members of this group.

Stereotype threat has been demonstrated to affect individuals during many tasks including math exams (Spencer, Steele, \& Quinn, 1999), athletic performance (Stone, Lynch, Sjomeling, \& Darley, 1999), and memory tests (Levy, 1996). These effects have been observed in stages of development ranging from middle school students (Oyserman, Gant, \& Ager, 1995) to the elderly (Levy, 1996).

Of particular concern in the present study are the effects of stereotype threat on women. Women earn $57 \%$ of in undergraduate degrees but only $30 \%$ in STEM fields (National Science Foundation, 2013). Despite performing at the same level as men in the classroom, women underperform in comparison on exams (Kimball, 1989). Numerous studies have concluded that women's math test performance is negatively affected by activating the "men are better than 
women at math" stereotype (e.g. Keller, 2002; Schmader \& Johns, 2003). It has been suggested that this may cause women to "disidentify" with math in order to avoid evaluation (Spencer et al., 1999).

\section{Proposed mechanisms}

While the presence of stereotype threat effects on achievement has been well established (e.g. Steele \& Aronson, 1995) the mechanisms leading to decreased performance have not. In the present study, we examine four potential mediating mechanisms: anxiety and SNS arousal, decreased working memory capacity, mindset, and effort.

Anxiety and SNS arousal. One often hypothesized mechanism is anxiety, however the findings for this relationship have been inconsistent. Steele and Aronson (1995) administered the State-Trait Anxiety Instrument (STAI) to test the hypothesis that knowing one is the potential target of a stereotype would cause anxiety, but were unable to detect any difference in anxiety levels among participants. Subsequent studies have attempted to link anxiety to stereotype threat using the STAI (Aronson et al., 1999; Schmader, 2002), word-fragment completion tests (Brown \& Josephs, 1999), and self-report anxiety surveys (Stone et al., 1999), yet have failed to link increased anxiety with decreased performance.

On the other hand several studies have found support for the anxiety hypothesis. Spencer, et al. (1999) measured the amount of time participants spent on each question while taking a math test, finding that the relationship between stereotype threat and test performance was partially mediated by anxiety. Likewise, Osborne (2001) used a self-report anxiety survey to measure the relationship, finding that performance was partially mediated by anxiety among African Americans, Latinos, and women.

A related mechanism is SNS arousal. O'Brien and Crandall (2003) pointed to research 
demonstrating that high arousal levels interfere with task performance in hypothesizing this relationship, arguing that the effects of arousal - increased heart rate, blood pressure, sweating, and epinephrine levels - would lead to automatic stress responses which inhibit prefrontal cortex function needed for difficult tasks, resulting in poor performance, but would enhance performance on easy tasks. The results of several studies have supported this hypothesis. Blascovich, Spencer, Quinn, and Steele (2001) found elevated blood pressure levels in African Americans under a threat condition, while the blood pressure of African Americans who were subject to a reduced threat condition was not higher than that of white participants. Vick, Seery, Blascovich, \& Weisbuch (2008) showed that women under stereotype threat conditions experienced biological markers of arousal associated with a threat motivational state which impairs performance, yet elimination of the threat led to markers associated with a challenge motivational state which enhanced performance.

Decreased working memory capacity. Working memory capacity has also been suggested as a mechanism of stereotype threat. Quinn and Spencer (2001) attributed their finding that fewer problem solving strategies were generated by women when stereotype threat conditions were present to a decrease in cognitive resources. This hypothesis was further tested by Schmader and Johns (2003), who found that women primed for stereotype threat demonstrated lower working memory capacity than men and women in the non-threat condition. Similarly, Croizet et al., (2004) found an association between poor performance due to stereotype threat and decreased heart rate variability, a physiological indication of mental load.

Beilock et al. (2007) tested performance under stereotype threat on two types of math problems. The results showed that participants suffered impaired performance only on problems presented horizontally, which rely more heavily on working memory. Additionally, participants 
continued to show stereotype threat effects in subsequent tasks which are processed in the same way. These findings supporting working memory capacity as a mechanism for stereotype threat led the researchers to propose two ways in which worry due to stereotype threat may reduce working memory. First, they point to research by Ashcraft and Kirk (2001) which suggests central executive processes are occupied by worries about performance, reducing the ability to focus attention and effort. Second, they hypothesize that worry may deplete the phonological components of working memory which are involved in thinking and inner speech.

Mindset. The individual's view of their own intelligence is another potential mechanism of stereotype threat. Dweck (2000) suggests that individuals holding an "incremental" view of intelligence, believing intelligence is a malleable trait, experience less anxiety than those with an "entity" view, who believe it is a fixed trait. Aronson and his colleagues (e.g. Aronson et al., 2002; Good, Aronson, Inzlicht, 2003) have shown that stereotype threat can be reduced by encouraging members of stereotyped groups to view intelligence as malleable. Good et al. (2003) analyzed test scores on the Texas Assessment of Academic Skills (TAAS) test after assigned mentors to teach junior high school students one of four messages. While female students in the control condition, who received an anti-drug message, performed worse than male students, this gap disappeared when students were taught about the expandable nature of intelligence.

Effort. Stereotype threat may also be mediated by the effort of the threatened individual. Steele and Aronson (1995) found that participants in the threat condition took longer to answer exam questions and answered fewer questions than participants in control conditions. Similarly, Stone (2002) found that activating a stereotype about poor athletic ability in whites caused participants to self-handicap by reducing effort in order to provide an alternative explanation for 
underperformance. However, studies using both self-report and behavioral measures have failed to find support for reduced effort as a mediator (Smith, 2004).

Summary of mechanisms. Previous research suggests four ways in which stereotype threat could potentially effect math test performance. First, an individual may experience anxiety and SNS arousal, leading to automatic stress responses which inhibit prefrontal cortex function needed for difficult tasks. Next, worry may occupy working memory capacity, reducing the individual's ability to focus attention and effort. Alternatively, a fixed intelligence mindset may cause the individual to believe in the accuracy of the stereotype. Finally, each of these factors may contribute to reduced effort.

\section{Mindfulness}

One potential way to decrease ST is mindfulness (Roeser \& Pinela, 2014). In recent years, an increasing amount of research has been devoted to understanding what mindfulness is and how it works (Shapiro, Carlson, Astin, \& Freedman, 2005). Though its roots are in Buddhist contemplative practices and philosophy, mindfulness shares ideas with other traditions including ancient Greek philosophy; phenomenology, existentialism, and naturalism in later Western European thought; and transcendentalism and humanism in America (Brown, Ryan, \& Creswell, 2007). Within psychological literature, mindfulness has been defined in several ways. The definition most commonly relied upon is that mindfulness is "the awareness that emerges through paying attention in a particular way: on purpose, in the present moment, and nonjudgmentally" (Kabat-Zinn, 1994).

\section{Outcomes}

Increased emotion regulation, increased attention regulation, change in perspective of self, and greater resources available to devote to learning have been suggested as positive 
outcomes of mindfulness (Hölzel, et al. 2011; Langer \& Moldoveanu, 2000; Blair \& Diamond, 2008). These findings suggest several ways in which mindfulness may reduce the effect of stereotype threat.

Increased emotion regulation. Emotions are improperly regulated when individuals avoid or become preoccupied with them (Hayes \& Feldman, 2004), both of which have been associated with negative physical and psychological health (Salovey, Rothman, Detweiler, \& Steward, 2002; Segerstrom, Stanton, Alden, \& Shortridge, 2003). Emotion regulation allows an individual to influence the emotions we have, when we have them, and one's experience and expression of them (Gross, 1998). The model suggested by Hölzel, et al. (2011) suggests two ways in which mindfulness enables emotion regulation: reappraisal and extinction.

Garland, Gaylord, \& Fredrickson (2011) suggest that positive reappraisal - "the adaptive process through which stressful events are re-construed as benign, beneficial, and/or meaningful" - is a cognitive coping strategy facilitated by mindfulness. This key process is often referred to in mindfulness literature as repercieving (Shapiro et al., 2006) or reconsolidation (Vago \& Silbersweig, 2012), and in psychological literature as psychological distance (Trope \& Liberman, 2010).

When a conditioned stimulus is repeatedly presented without the corresponding unconditioned stimulus, extinction of the conditioned response occurs (Lovibond, Davis, \& O'Flaherty (2000). Meditators allow themselves to be affected by experiences by turning toward them rather than away (Santorelli, 2000), thereby allowing extinction to occur. Mindfulness has been shown to increase activation (Lazar et al., 2000) and produce long term structural changes in areas of the brain associated with extinction (Hölzel et al., 2008).

Increased attention regulation. It could be that mindfulness helps stereotyped group 
members to become aware of and regulate ST effects. Focused attention meditation involves placing attention on a single object and returning it to this object each time the attention wanders (Hölzel et al., 2011) and has been shown to enhance attention regulation in experienced meditators (Valentine \& Sweet, 1999; Jha, Krompinger, \& Baime, 2007). Hölzel et al. (2007) used fMRI to compare experienced meditators to control groups and found greater activation among the meditators of the anterior cingulate cortex (ACC), which regulates executive attention (van Veer \& Carter, 2002). Additionally, meditation has been found to produce long term changes in the ACC. Grant, Courtemanche, Duerden, Duncan, \& Rainville (2010) found greater cortical thickness in the dorsal ACC of experienced meditators, while Tang et al. (2010) found an increase in white matter after 11 hours of meditation.

Change in perspective of self. According to Langer (1992), mindfulness is a "state of openness to novelty in which the individual actively constructs categories and distinctions." Teachings within the Buddhist tradition emphasize that the perception of the self is an ongoing process (Hölzel et al., 2011). According to these teachings, psychological distress results when one views self as a permanent and unchanging thing (Olendzki, 2010), and change in perspective of self is a key to discovering enduring happiness (Hölzel et al., 2011). By entering a state of mindfulness, individuals can escape rigid mindsets in order to become sensitive to context and perspective when processing information. Several studies of mindfulness have documented changes in self-report scores of self-concept (e.g. Emavardhana \& Tori, 1997; Haimerl \& Valentine, 2001) as well as changes in self-referrential processing within the brain (Farb et al., 2007).

Greater resources available to devote to learning. Self-regulation refers to "the selfdirective process by which learners transform their mental abilities into academic skills" 
(Zimmerman, 2002). This ability has often been associated with executive functioning (EF), a set

of cognitive processes including working memory, inhibitory control of automatic responses, and mental flexibility (Blair \& Diamond, 2008). Researchers have found correlations between mindfulness exercises and increases in EF leading to increased working memory capacity (Chambers, Lo, \& Allen, 2008), decreases in anxiety and automatic processing (Napoli, Krech, \& Holley, 2005; Moore, \& Malinowski, 2009), and mental set shifting (Miyake, Friedman, Emerson, Witzki, \& Howerter, 2000). One benefit of increased self-regulation and EF is that the individual has greater resources available to devote to learning. Individuals who successfully self-regulate tend to believe they are more capable, which leads to greater effort to learn (Blair \& Diamond, 2008).

\section{Linking mindfulness and stereotype threat}

We proposed four mechanisms - anxiety and SNS arousal, decreased working memory capacity, mindset, and effort - by which mindfulness could potentially help to reduce the negative impact of SA on test performance. . Previous research has demonstrated that mindfulness practices can be effective in producing positive outcomes in each of these areas. Therefore, we hypothesize that mindfulness practice will allow stereotype threatened individuals to regulate anxiety and SNS arousal (increased emotion regulation), focus on the math test (increased attention regulation), view their own intelligence as malleable (change in perspective of self), and increase their effort on the test (greater resources available to devote to learning), thereby decreasing or eliminating the effect of stereotype activation on test performance and resulting in normal performance.

\section{Prior research}

To this point, only one study has attempted to test mindfulness as an intervention to 
stereotype threat. Weger, Hooper, Meier, and Hopthrow (2011) found a reduced impact of stereotype threat in mindfulness condition $\left(F(1,67)=4.39, \mathrm{p}=.04, \eta^{2}=.061\right)$. While these results are encouraging, the proposed study will extend this line of research in two important ways. In the previous study participants were told they were taking part in a test to explore "why males are better than females in maths". While stereotype threat can be primed in an overt manner such as this, research has shown the threat can also be activated in through subconscious priming (e.g. Steele \& Aronson, 1995). Stone and McWhinnie (2008) have suggested that stereotype threat primed implicitly may operate differently than when primed explicitly, therefore the use of an implicit prime will allow us to explore the use of a mindfulness intervention in a situation that more closely parallels the manner in which stereotype threat occurs in real-world situations. Second, the previous study found a small effect size for the interaction between mindfulness and stereotype threat. We believe a breath-focused meditation may produce a greater range of outcomes than the "raisin task" used in the previous study, and thus hypothesize that the use of a breath-focused meditation will result in a larger effect.

\section{Methods}

\section{Sample}

The study sample included 35 university students, ages 18-31. The sample was ethnically diverse, composed of $61 \%$ Caucasian, 21\% Asian, 11\% Hispanic/Latino, 4\% Native American, $4 \%$ declined to answer. Male participants were recruited to allow us to include "mixed gender" groups in the testing situation and thereby enhance our stereotype threat manipulation around gender and math performance. However, because we were only looking at differences in female performance between the 4 conditions, data from male participants was not analyzed, resulting in a sample of 28 female students. 


\section{Design}

This was a female-only, randomized experiment with 4 conditions. Group 1, the baseline condition against which we compared the other conditions was the Stereotype Activation (SA) Alone condition $(n=5)$. The math performance and related psychological processes of females in this group were compared to females in the three other conditions of the study, including Group 2 - No Stereotype Activation $(n=6)$, Group 3 - SA + Relaxation $(n=10)$, and Group $4-S A+$ Mindfulness Meditation ( $\mathrm{n}=7)$. The independent variable was the randomly assigned condition. The dependent variable was math achievement and the potential mechanisms examined included participant mood, metacognitive awareness, mindset, and effort on math assessment.

\section{Experimental Procedure}

Participants were initially recruited from an undergraduate psychology course and given course credit for their participation. Alternatively, students who did not wish to participate in the study were offered the opportunity to earn credit by writing a 2-page reflection paper. A second group of participants were recruited using an email announcement offering entry into a raffle for a \$100 gift card in exchange for participation.

After agreeing to participate in the study, subjects were randomly assigned to one of the four experimental conditions. Data collection took place in computer lab sessions. Upon arrival at the lab, participants were seated at a computer and asked to follow on-screen instructions. After giving consent to participate in the research, participants were asked to fill out demographic information. In the SA conditions (SA Alone, SA + Mindfulness Meditation, and $\mathrm{SA}+$ Relaxation) this survey included questions about the gender of the participant and number of math courses taken in order to activate a stereotype concerning female ability in math. After 
completing the survey participants in the SA + Mindfulness Meditation and SA + Relaxation conditions were asked to put on headphones and follow the instructions within the audio file before taking the test, then played an mp3 through containing either meditation instructions or music. Participants were then given the math test followed by the post-test engagement survey before being debriefed. In order to conceal the true nature of the experiment, the SA + Mindfulness Meditation and SA + Relaxation conditions were tested separately from the SA Alone and No SA conditions because these conditions required headphones and silent listening whereas the others did not.

\section{Experimental Manipulations}

In each of the three SA conditions, we activated the stereotype by asking participants to indicate their gender and the number of math courses they have taken in college. After activation, Participants in the SA + Mindfulness Meditation and SA + Relaxation conditions received on-screen instructions to put on headphones and listen to an audio file embedded into the survey. Participants in the SA + Mindfulness Meditation condition received a 10 minute mp3 file containing instructions for a breath meditation. Participants in the SA + Relaxation condition received a 10 minute mp3 file containing instrumental music. Participants in the SA Only condition received no additional manipulation before beginning the test.

\section{Measures}

Three sets of measures were assessed. Math achievement was measured with a 20 item test containing sample GRE questions (e.g. How many real roots does the polynomial $2 x 5+8 x-$ 7 have?, see Appendix A for math items). This type of measure is consistent with those used in previous stereotype threat research (e.g. Steele \& Aronson, 1995; Spencer et al., 1999; Schmader \& Johns, 2003; Jamieson, \& Harkins, 2009). The Math Achievement variable was computed by 
adding the total number of right answers and dividing the result by the total number of questions $(\mathrm{M}=29.46, \mathrm{SD}=12.57)$.

A 17 item survey was administered immediately after students took the math achievement test (see Appendix B for post-test survey). This survey included 10-point Likert scale measures (e.g., How would you rate your energy level during the test?, 1=low, 5=moderate, $10=$ high) of 4 potential mechanisms: Pleasantness and energy level - two dimensions of mood to derive emotional experience following the math achievement test (derived from Feldman Barrett \& Russell, 1998), metacognitive awareness (O’Neil \& Abedi, 1996), mindset - a measure of the participants view of the nature of intelligence (Dweck, 2000), and effort expended during the test (Lau \& Roeser, 2002).

\section{Results}

The primary goal of this research was to investigate the impact of a mindfulness exercise on performance in stereotype threat situations. Our first research question examined whether SA led to decreased female achievement in math compared to no SA; and our second research question examined whether completing a mindfulness exercise or listening to relaxation music would reduce the effects of SA. To address both questions, a one-way analysis of variance with post-hoc comparisons was done.

The effects of condition on performance were evaluated with a one-way (math achievement $\mathrm{x}$ condition) ANOVA. Group Means, Standard Deviations, and F - values are presented in Table 1. The ANOVA results indicated a significant main effect for condition, $F(3,24)=5.133, p<.01$. Post-hoc analyses were used to ascertain the specific group differences contributing to the overall group effect. To conserve degrees of freedom and therefore, the power to detect between sub-group differences in this small sample, Dunnett's post-hoc tests 
were used in which each group was compared to SA Alone - the baseline condition in this study.

Table 1

Performance and Potential Mechanism Group Means, Standard Deviations, and F - values

\begin{tabular}{lccccc}
\hline & $\begin{array}{c}\text { Stereotype } \\
\text { Activation } \\
\text { Only }\end{array}$ & $\begin{array}{c}\text { No Stereotype } \\
\text { Activation }\end{array}$ & $\begin{array}{c}\text { Stereotype } \\
\text { Activation }+ \\
\text { Relaxation }\end{array}$ & $\begin{array}{c}\text { Stereotype } \\
\text { Activation }+ \\
\text { Mindfulness }\end{array}$ & $F$ - value \\
\hline Math & $.24^{\mathrm{a}}$ & $.22^{\mathrm{a}}$ & $.28^{\mathrm{a}}$ & $.42^{\mathrm{b}}$ & 5.10 \\
Achievement & $(6.52)$ & $(12.91)$ & $(9.78)$ & $(11.13)$ & \\
Mood - & $4.60^{\mathrm{a}}$ & $5.33^{\mathrm{a}}$ & $5.50^{\mathrm{a}}$ & $5.57^{\mathrm{a}}$ & 0.19 \\
Pleasantness & $(1.95)$ & $(2.88)$ & $(2.32)$ & $(2.37)$ & \\
Mood - & $4.50^{\mathrm{a}}$ & $4.00^{\mathrm{a}}$ & $4.60^{\mathrm{a}}$ & $5.14^{\mathrm{a}}$ & 0.29 \\
Energy & $(3.11)$ & $(1.55)$ & $(1.84)$ & $(2.67)$ & \\
Metacognitive & $2.68^{\mathrm{a}}$ & $2.73^{\mathrm{a}}$ & $3.10^{\mathrm{a}}$ & $3.48^{\mathrm{a}}$ & \\
Awareness & $(0.57)$ & $(0.68)$ & $(0.58)$ & $(0.59)$ & 0.36 \\
Motivational & $2.00^{\mathrm{a}}$ & $2.08^{\mathrm{a}}$ & $2.00^{\mathrm{a}}$ & $1.64^{\mathrm{a}}$ & \\
Mindset & $(0.82)$ & $(0.97)$ & $(0.85)$ & $(0.75)$ & 3.20 \\
Effort During & $5.00^{\mathrm{a}}$ & $5.83^{\mathrm{a}}$ & $7.50^{\mathrm{b}}$ & $7.86^{\mathrm{b}}$ & \\
Math Tests & $(2.12)$ & $(2.48)$ & $(1.65)$ & $(1.46)$ & \\
\hline
\end{tabular}

Hypothesis 1 was that participants in the SA Alone condition would suffer decreased performance in comparison to participants in the No SA condition. Dunnet's post-hoc comparisons did not find significant differences between the SA Only and the No SA conditions.

Hypothesis 2 was that mindfulness after SA would improve performance in comparison to SA alone. As predicted, Dunnet's post-hoc comparisons showed that participants in the SA + Mindfulness Meditation condition scored higher $(M=.42)$ on the math test than participants in the SA Alone $(M=.24)$ condition.

Hypothesis 3 was that relaxation after SA would improve performance in comparison to SA alone. Dunnet's post-hoc comparisons did not find significant differences between SA + Relaxation and the SA Only conditions.

The second goal of this research was to identify potential mediating mechanisms of 
stereotype threat effects on performance which differ by condition. Hypothesis 4 was that condition might be associated with the mood of the participants. We expected that participants in the SA + Mindfulness Meditation condition would report higher levels of pleasantness and energy following the math test than participants in the SA + Relaxation and SA Alone conditions. The results of a one-way ANOVA showed that the effect for group on pleasantness was non-significant, $F(3,24)=.19 p=.90$ The results of a one-way ANOVA for energy level by group was also non-significant, $F(3,24)=.29, p=.84$. In addition, we asked participants to choose one word to describe their mood during the test. These words were coded as either positive, neutral, or negative using items from the Positive and Negative Affect Schedule (PANAS) (Watson, Clark, \& Tellegen, 1988). Results of a Chi-square test showed no significant relationship between condition and the words used to describe the participants' $\operatorname{mood} \chi^{2}(6, N=$ 28) $=4.65 p=.59$.

Hypothesis 5 was that condition might also be associated with greater metacognitive awareness of the participants. We expected that participants in the Mindfulness Meditation condition would report a greater level of metacognitive awareness following the math test than participants in the SA + Relaxation and SA Alone conditions. The results of a one-way ANOVA showed that the effect for group on metacognitive awareness was non-significant, $F(3,23)=2.21$ $p=.11$

Hypothesis 6 was that condition might also be associated with the intelligence mindset of the participants. We expected that participants in the SA + Mindfulness Meditation and SA + Relaxation conditions would be more likely to report a growth intelligence mindset than participants in the SA Only condition. The results of a one-way ANOVA showed that the effect for group on mindset was non-significant, $F(3,23)=.36, p=.78$. 
Hypothesis 7 was that condition might also be associated with the effort of the participants. We expected that participants in the SA + Mindfulness Meditation and SA + Relaxation conditions would be more likely than participants in the SA Only condition to report trying their best on the math test. The results of a one-way ANOVA (effort x condition) showed a significant main effect for condition, $F(3,24)=3.20, p=.04$. As predicted, Dunnet's post-hoc comparisons showed that participants in the SA + Mindfulness Meditation $(M=7.86, p=.02)$ and SA + Relaxation $(M=7.50, p=.03)$ conditions reported greater effort on the test (indicative of more psychological resources) than participants in the SA Alone $(M=5.00)$ condition.

\section{Discussion}

While the negative effects of an activated stereotype on the performance of stereotyped group members have been well established, few researchers have sought to identify ways to alleviate these effects after activation. The primary purpose of this study was to test the effectiveness of mindfulness and relaxation exercises as an intervention for stereotype threat effects. We predicted that following activation with a 10 minute mindfulness exercise, four outcomes of mindfulness - improved mood, metacognitive awareness, growth intelligence mindset, and effort during the exam - would reduce or extinguish the effects of an activated stereotype. The significant effect of condition on math achievement provides preliminary evidence for our hypothesis that this intervention would reduce the performance-undermining effects of an activated stereotype. This finding is important for two key reasons.

First, it supports the idea that the effects of stereotype threat can be alleviated once the threat has occurred. A majority of prior research on stereotype threat interventions has focused on shaping participants view of intelligence before the threat is primed (e.g. Aronson et al., 2002; Good, Aronson, \& Inzlicht, 2003). Our finding is consistent with the research of Ambady, Paik, 
Steele, Owen-Smith, \& Mitchell (2004), who found that an individuation task requiring female participants to answer questions about themselves allowed themselves to disassociate themselves with female stereotypes after activation.

A second important implication of this finding is the idea that a single, brief mindfulness exercise can be effective as an intervention. The most commonly cited mindfulness interventions such as mindfulness-based stress reduction (MBSR) (Davidson et al., 2003) and mindfulnessbased cognitive therapy (MBCT) (Kaviani, Javaheri, \& Hatami, 2011) are 8 week programs with normal sessions ranging from 2-2.5 hours (Baer, 2003). While a few shorter interventions have been found effective (e.g. Mackenzie, Poulin, \& Seidman-Carlson, 2006; Winzelberg \& Luskin, 1999; Tang et al., 2010) these interventions range from 3-4 hours and are significantly longer than the 10-minute meditation used in the present study. The significant difference detected between the SA + Mindfulness Meditation and SA only conditions provides further support for Weger et al. (2012), who found a 5-minute mindfulness exercise to be effective.

Another important finding of this study is the relationship between stereotype threat and effort. Our hypothesis that the performance-undermining effects of an activated stereotype would be mediated by the effort of the participants was supported by the significant effect of effort on math achievement. While both the SA + Mindfulness Meditation and SA + Relaxation conditions reported greater effort, only participants in the SA + Mindfulness Meditation condition performed better on the math test. These findings suggest that both interventions had calming effects which allowed the individual to cope with the threat situation, but that participants in the mindfulness condition also received some additional cognitive benefit. While we were unsuccessful in detecting the effects of the other proposed mechanisms, we suspect that that one or more of these factors may have contributed to the performance effects of the 
mindfulness intervention by allowing the individuals to allocate additional resources to the test rather than focusing on the threat. In particular, the near-significant effect of metacognitive awareness may be an indication of its contribution to the mindfulness intervention's positive effect on performance.

Although the results of this study have important implications, it is important to note the limitations of our findings. This study was limited by its relatively small sample size. In particular, we suspect this may be the reason we failed detect significant differences in achievement between the No SA and SA only conditions. Given the numerous studies which have established stereotype threat among females when they believe their math achievement will be compared to males (e.g. Spencer et al., 1999; Keller, 2002) and the significant difference detected between the SA + Mindfulness Meditation and SA only conditions, we suspect that stereotype threat was in fact invoked and the mindfulness intervention was successful.

This study may also be limited by the measures used. Sample GRE questions have been established as a measure of performance in a stereotype threat situation through their use in many previous studies (e.g. Steele \& Aronson, 1995). However, mean test scores in this study $(M=.29)$ were significantly lower than in previous research (e.g. Schmader \& Johns, 2003, $M=.49$ in threat condition). Although this might be a reflection of the small sample size, it may also be possible that the questions selected were more difficult than those used in previous research. Another possible explanation is that we may not have masked the purpose of the study well enough, and therefore participants lacked the motivation to take seriously the math items resulting in low scores. In order to avoid this uncertainty, future researchers should seek to assess the difficulty of math performance measures before they are adopted.

The self-report items used to assess potential mechanisms were adopted from previous 
research unrelated to stereotype threat, and may not be accurate measures of stereotype threat mechanisms. Future research should seek to use more established measures such as real-time physiological measures for anxiety and SNS arousal (e.g. blood pressure, perspiration) and working memory (e.g. eye tracking, EEG), a six item intelligence mindset instrument consistent with previous research (Blackwell, Trzesniewski, \& Dweck, 2007), and behavioral measures of effort (e.g. time spent on math test).

While the majority of stereotype threat researchers have tested participants individually, a few studies (e.g. Croizet \& Claire, 1998) have tested participants in groups. Because testing in a mixed-gender group can make an individual's identity and related stereotypes more salient (Good et al., 2003), we chose this method in order to more accurately simulate the way stereotypes are activated in real-world situations.

Additionally, stereotype threat has been demonstrated to affect various groups in many different contexts. The present study focused solely on performance of female college students in order to eliminate possible confounds. While we suspect that these results would generalize to other threat situations, we cannot assume that this is the case. Future research should test a mindfulness intervention in threat situations affecting populations other than female college students and involving tasks other than test performance. 


\section{References}

Ambady, N., Paik, S. K., Steele, J., Owen-Smith, A., \& Mitchell, J. P. (2004). Deflecting negative self-relevant stereotype activation: The effects of individuation. Journal of Experimental Social Psychology, 40(3), 401-408.

Aronson, J., Fried, C. B., \& Good, C. (2002). Reducing the effects of stereotype threat on African American college students by shaping theories of intelligence. Journal of Experimental Social Psychology, 38(2), 113-125.

Aronson, J., Lustina, M. J., Good, C., Keough, K., Steele, C. M., \& Brown, J. (1999). When white men can't do math: Necessary and sufficient factors in stereotype threat. Journal of Experimental Social Psychology, 35(1), 29-46.

Aronson, J., \& Salinas, M. F. (1997). Stereotype threat, attributional ambiguity, and Latino underperformance. Unpublished manuscript, University of Texas.

Ashcraft, M. H., \& Kirk, E. P. (2001). The relationships among working memory, math anxiety, and performance. Journal of Experimental Psychology: General, 130(2), 224.

Baer, R. A. (2003). Mindfulness training as a clinical intervention: A conceptual and empirical review. Clinical psychology: Science and practice, 10(2), 125-143.

Beilock, S. L., Rydell, R. J., \& McConnell, A. R. (2007). Stereotype threat and working memory: mechanisms, alleviation, and spillover. Journal of Experimental Psychology: General, 136(2), 256.

Blair, C., \& Diamond, A. (2008). Biological processes in prevention and intervention: The promotion of self-regulation as a means of preventing school failure. Development and psychopathology, 20(03), 899-911.

Blascovich, J., Spencer, S. J., Quinn, D., \& Steele, C. (2001). African Americans and high blood 
pressure: The role of stereotype threat. Psychological Science, 12(3), 225-229.

Blackwell, L. S., Trzesniewski, K. H., \& Dweck, C. S. (2007). Implicit theories of intelligence predict achievement across an adolescent transition: A longitudinal study and an intervention. Child development, 78(1), 246-263.

Bosson, J. K., Haymovitz, E. L., \& Pinel, E. C. (2004). When saying and doing diverge: The effects of stereotype threat on self-reported versus non-verbal anxiety. Journal of Experimental Social Psychology, 40(2), 247-255.

Brown, K. W., Goodman, R. J., \& Inzlicht, M. (2013). Dispositional mindfulness and the attenuation of neural responses to emotional stimuli. Social Cognitive and Affective Neuroscience, 8(1), 93-99.

Brown, R. P., \& Josephs, R. A. (1999). A burden of proof: Stereotype relevance and gender differences in math performance. Journal of Personality and Social Psychology, 76(2), 246.

Brown, K. W., Ryan, R. M., \& Creswell, J. D. (2007). Mindfulness: Theoretical foundations and evidence for its salutary effects. Psychological Inquiry, 18(4), 211-237.

Chambers, R., Lo, B. C. Y., \& Allen, N. B. (2008). The impact of intensive mindfulness training on attentional control, cognitive style, and affect. Cognitive Therapy and Research, 32(3), 303-322.

Croizet, J. C., \& Claire, T. (1998). Extending the concept of stereotype threat to social class: The intellectual underperformance of students from low socioeconomic backgrounds. Personality and Social Psychology Bulletin, 24(6), 588-594.

Croizet, J. C., Després, G., Gauzins, M. E., Huguet, P., Leyens, J. P., \& Méot, A. (2004). Stereotype threat undermines intellectual performance by triggering a disruptive mental 
load. Personality and Social Psychology Bulletin, 30(6), 721-731.

Davidson, R. J., Kabat-Zinn, J., Schumacher, J., Rosenkranz, M., Muller, D., Santorelli, S. F., \& Sheridan, J. F. (2003). Alterations in brain and immune function produced by mindfulness meditation. Psychosomatic Medicine, 65(4), 564-570.

Davis, C., Aronson, J., \& Salinas, M. (2006). Shades of threat: Racial identity as a moderator of stereotype threat. Journal of Black Psychology, 32, 399-417.

Dweck, C. S. (2000). Self-theories: Their role in motivation, personality, and development. Psychology Press.

Emavardhana, T., \& Tori, C. D. (1997). Changes in self-concept, ego defense mechanisms, and religiosity following seven-day Vipassana meditation retreats. Journal for the Scientific Study of Religion, 194-206.

Farb, N. A., Segal, Z. V., Mayberg, H., Bean, J., McKeon, D., Fatima, Z., \& Anderson, A. K. (2007). Attending to the present: mindfulness meditation reveals distinct neural modes of self-reference. Social Cognitive and Affective Neuroscience, 2(4), 313-322.

Feldman Barrett, L., \& Russell, J. A. (1998). Independence and bipolarity in the structure of affect. Journal of Personality and Social Psychology, 74, 967-984.

Garland, E. L., Gaylord, S. A., \& Fredrickson, B. L. (2011). Positive reappraisal mediates the stress-reductive effects of mindfulness: An upward spiral process. Mindfulness, 2(1), 5967.

Good, C., Aronson, J., \& Inzlicht, M. (2003). Improving adolescents' standardized test performance: An intervention to reduce the effects of stereotype threat. Journal of Applied Developmental Psychology, 24(6), 645-662.

Grant, J. A., Courtemanche, J., Duerden, E. G., Duncan, G. H., \& Rainville, P. (2010). Cortical 
thickness and pain sensitivity in zen meditators. Emotion, 10(1), 43

Gross, J. J. (1998). Antecedent-and response-focused emotion regulation: divergent consequences for experience, expression, and physiology. Journal of Personality and Social Psychology, 74(1), 224.

Haimerl, C. J., \& Valentine, E. R. (2001). The effect of contemplative practice on intrapersonal, interpersonal, and transpersonal dimensions of the self-concept. Journal of Transpersonal Psychology, 33(1), 37-52.

Hayes, A. M., \& Feldman, G. (2004). Clarifying the construct of mindfulness in the context of emotion regulation and the process of change in therapy. Clinical Psychology: Science and Practice, 11(3), 255-262.

Hoffman, S. G., Sawyer, A. T., Witt, A. A., \& Oh, D. (2010). The effect of mindfulness-based therapy on anxiety and depression: A meta-analytic review. Journal of Consulting and Clinical Psychology, 78(2), 169.

Hölzel, B. K., Lazar, S. W., Gard, T., Schuman-Olivier, Z., Vago, D. R., \& Ott, U. (2011). How does mindfulness meditation work? Proposing mechanisms of action from a conceptual and neural perspective. Perspectives on Psychological Science, 6(6), 537-559.

Hölzel, B. K., Ott, U., Gard, T., Hempel, H., Weygandt, M., Morgen, K., \& Vaitl, D. (2008). Investigation of mindfulness meditation practitioners with voxel-based morphometry. Social Cognitive and Affective Neuroscience, 3(1), 55-61.

Hölzel, B. K., Ott, U., Hempel, H., Hackl, A., Wolf, K., Stark, R., \& Vaitl, D. (2007). Differential engagement of anterior cingulate and adjacent medial frontal cortex in adept meditators and non-meditators. Neuroscience Letters, 421(1), 16-21.

Jamieson, J. P., \& Harkins, S. G. (2009). The effect of stereotype threat on the solving of 
quantitative GRE problems: A mere effort interpretation. Personality and Social Psychology Bulletin, 35(10), 1301-1314.

Jha, A. P., Krompinger, J., \& Baime, M. J. (2007). Mindfulness training modifies subsystems of attention. Cognitive, Affective, \& Behavioral Neuroscience, 7(2), 109-119.

Jha, A. P., Stanley, E. A., Kiyonaga, A., Wong, L., \& Gelfand, L. (2010). Examining the protective effects of mindfulness training on working memory capacity and affective experience. Emotion, 10(1), 54.

Kabat-Zinn, J. (1994). Wherever you go, there you are: Mindfulness meditation in everyday life. Hyperion.

Kaviani, H., Javaheri, F., \& Hatami, N. (2011). Mindfulness-based Cognitive Therapy (MBCT) Reduces Depression and Anxiety Induced by Real Stressful Setting in Nonclinical Population. International Journal of Psychology and Psychological Therapy, 11(2), 285296.

Keller, J. (2002). Blatant stereotype threat and women's math performance: Self-handicapping as a strategic means to cope with obtrusive negative performance expectations. Sex Roles, 47(3-4), 193-198.

Kimball, M. M. (1989). A new perspective on women's math achievement. Psychological Bulletin, 105(2), 198.

Lau, S., \& Roeser, R. W. (2002). Cognitive abilities and motivational processes in high school students' situational engagement and achievement in science. Educational Assessment, 8(2), 139-162.

Langer, E. J. (1992). Matters of mind: Mindfulness/mindlessness in perspective.Consciousness and cognition, 1(3), 289-305. 
Langer, E. J., \& Moldoveanu, M. (2000). The construct of mindfulness. Journal of Social Issues, $56(1), 1-9$.

Lazar, S. W., Bush, G., Gollub, R. L., Fricchione, G. L., Khalsa, G., \& Benson, H. (2000). Functional brain mapping of the relaxation response and meditation. Neuroreport, 11(7), $1581-1585$.

Levy, B. (1996). Improving memory in old age through implicit self-stereotyping. Journal of Personality and Social Psychology, 71(6), 1092.

Lovibond, P. F., Davis, N. R., \& O'Flaherty, A. S. (2000). Protection from extinction in human fear conditioning. Behaviour Research and Therapy, 38(10), 967-983.

Mackenzie, C. S., Poulin, P. A., \& Seidman-Carlson, R. (2006). A brief mindfulness-based stress reduction intervention for nurses and nurse aides. Applied Nursing Research, 19(2), $105-$ 109.

Moore, A., \& Malinowski, P. (2009). Meditation, mindfulness and cognitive flexibility. Consciousness and Cognition, 18(1), 176-186.

Napoli, M., Krech, P. R., \& Holley, L. C. (2005). Mindfulness training for elementary school students: The attention academy. Journal of Applied School Psychology, 21(1), 99-125.

National Science Foundation, Arlington, VA. (2000). Women, Minorities, and Persons with Disabilities in Science and Engineering: 2000. ERIC Clearinghouse.

O'Brien, L. T., \& Crandall, C. S. (2003). Stereotype threat and arousal: Effects on women's math performance. Personality and Social Psychology Bulletin, 29(6), 782-789.

Olendzki, A. (2010). Unlimiting mind: The radically experiential psychology of Buddhism. Wisdom Publications Inc.

O’Neil, H. F., Jr., \& Abedi, J. (1996). Reliability and validity of a state metacognitive inventory: 
Potential for alternative assessment. Journal of Educational Research, 89, 234-245.

Osborne, J. W. (2001). Testing stereotype threat: Does anxiety explain race and sex differences in achievement?. Contemporary Educational Psychology, 26(3), 291-310.

Oyserman, D., Gant, L., \& Ager, J. (1995). A socially contextualized model of African American identity: Possible selves and school persistence. Journal of Personality and Social Psychology, 69(6), 1216.

Quinn, D. M., \& Spencer, S. J. (2001). The interference of stereotype threat with women's generation of mathematical problem-solving strategies. Journal of Social Issues, 57(1), $55-71$

Salovey, P., Rothman, A. J., Detweiler, J. B., \& Steward, W. T. (2000). Emotional states and physical health. American Psychologist, 55, 110-121.

Schmader, T. (2002). Gender identification moderates stereotype threat effects on women's math performance. Journal of Experimental Social Psychology, 38(2), 194-201.

Schmader, T., \& Johns, M. (2003). Converging evidence that stereotype threat reduces working memory capacity. Journal of Personality and Social Psychology, 85(3), 440.

Segerstrom, S. C., Stanton, A. L., Alden, L. E., \& Shortridge, B. E. (2003). A multidimensional structure for repetitive thought: what's on your mind, and how, and how much?. Journal of Personality and Social Psychology, 85(5), 909.

Santorelli, S. (2000). Heal thy self: Lessons on mindfulness in medicine. New York, NY: Three Rivers Press.

Shapiro, S. L., Carlson, L. E., Astin, J. A., \& Freedman, B. (2006). Mechanisms of mindfulness. Journal of Clinical Psychology, 62(3), 373-386.

Smith, J. L. (2004). Understanding the process of stereotype threat: A review of mediational 
variables and new performance goal directions. Educational Psychology Review, 16(3), 177-206.

Spencer, S. J., Steele, C. M., \& Quinn, D. M. (1999). Stereotype threat and women's math performance. Journal of Experimental Social Psychology, 35(1), 4-28.

Steele, C. M., \& Aronson, J. (1995). Stereotype threat and the intellectual test performance of African Americans. Journal of Personality and Social Psychology, 69(5), 797-811.

Stone, J. (2002). Battling doubt by avoiding practice: The effects of stereotype threat on selfhandicapping in white athletes. Personality and Social Psychology Bulletin, 28(12), 1667-1678.

Stone, J., Lynch, C. I., Sjomeling, M., \& Darley, J. M. (1999). Stereotype threat effects on Black and White athletic performance. Journal of Personality and Social Psychology, 77(6), 1213.

Stone, J., \& McWhinnie, C. (2008). Evidence that blatant versus subtle stereotype threat cues impact performance through dual processes. Journal of Experimental Social Psychology, $44,445-452$.

Tang, Y. Y., Lu, Q., Geng, X., Stein, E. A., Yang, Y., \& Posner, M. I. (2010). Short-term meditation induces white matter changes in the anterior cingulate. Proceedings of the National Academy of Sciences, 107(35), 15649-15652.

Trope, Y., \& Liberman, N. (2010). Construal-level theory of psychological distance. Psychological review, 117(2), 440.

Valentine, E. R., \& Sweet, P. L. (1999). Meditation and attention: A comparison of the effects of concentrative and mindfulness meditation on sustained attention. Mental Health, Religion \& Culture, 2(1), 59-70. 
van Veen, V., \& Carter, C.S. (2002). The anterior cingulate as a conflict monitor: FMRI and ERP studies. Physiology \& Behavior, 77, 477-482.

Vago, D. R., \& Silbersweig, D. A. (2012). Self-awareness, self-regulation, and selftranscendence (S-ART): a framework for understanding the neurobiological mechanisms of mindfulness. Frontiers in Human Neuroscience, 6.

Vick, S. B., Seery, M. D., Blascovich, J., \& Weisbuch, M. (2008). The effect of gender stereotype activation on challenge and threat motivational states. Journal of Experimental Social Psychology, 44(3), 624-630.

Watson, D., Clark, L. A., \& Tellegen, A. (1988). Development and validation of brief measures of positive and negative affect: the PANAS scales. Journal of Personality and Social Psychology, 54(6), 1063.

Weger, U. W., Hooper, N., Meier, B. P., \& Hopthrow, T. (2012). Mindful maths: Reducing the impact of stereotype threat through a mindfulness exercise. Consciousness and Cognition, 21(1), 471-475.

Winzelberg, A. J., \& Luskin, F. M. (1999). The effect of a meditation training in stress levels in secondary school teachers. Stress and Health, 15(2), 69-77.

Zimmerman, B. J. (2002). Becoming a self-regulated learner: An overview. Theory into practice, 41(2), 64-70. 
Appendix A

Math Achievement Test

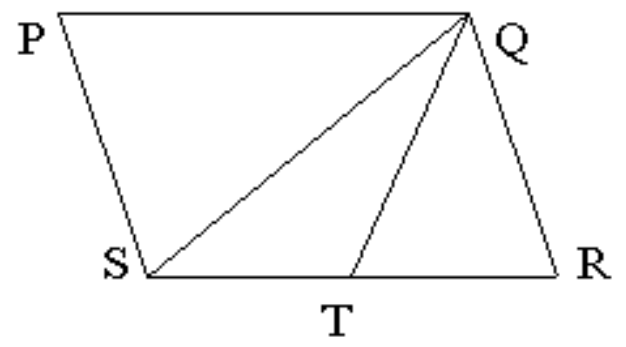

PQRS is a parallelogram and ST $=\mathrm{TR}$. What is the ratio of the area of triangle QST to the area of the parallelogram?
$1: 2$
$1: 3$
$1: 4$
$1: 5$
It cannot be determined

$\mathrm{x}$ is 3 less than $\mathrm{y}$

$$
\begin{array}{r|l}
\mathbf{x}+\mathbf{5} & \mathrm{y}+2 \\
\mathrm{C} & \text { The quantity on the left is greater } \\
\text { The quantity on the right is greater } \\
\text { Both are equal } \\
\text { The relationship cannot be determined without further information }
\end{array}
$$

In a certain game of 50 questions, the final score is calculated by subtracting twice the number of wrong answers from the total number of correct answers. If a player attempted all questions and received a final score of 35 , how many wrong answers did he give?

Let $\mathrm{k}$ be the number of real solutions of the equation $e^{x}+x-2=0$ in the interval $[0,1]$, and let $n$ be the number of real solutions that are not in $[0,1]$. Which of the following is true?

$$
\begin{aligned}
& \mathrm{k}=0 \text { and } \mathrm{n}=1 \\
& \mathrm{k}=1 \text { and } \mathrm{n}=0 \\
& \mathrm{k}=\mathrm{n}=1 \\
& \mathrm{k}>1 \\
& \mathrm{n}>1
\end{aligned}
$$


1453006101230

In the above sequence every term after the first is formed by multiplying by $\mathrm{x}$ and then adding $\mathrm{y}$, where $\mathrm{x}$ and $y$ are positive integers. What is the value of $x+y$ ?

The average (arithmetic mean) of four numbers is 36

\section{The sum of the same four numbers}

\section{0}

The quantity on the left is greater

The quantity on the right is greater

Both are equal

C The relationship cannot be determined without further information

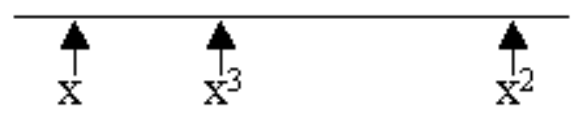

Considering the positions on the number line above, which of the following could be a value for $\mathrm{x}$ ?

Select ALL such values.
Г $5 / 3$
Г $3 / 5$
Г $-2 / 5$
Г $-3 / 4$
Г $-5 / 2$

A fair coin is tossed three times

The chances of getting 3 heads

The chances of getting no heads

The quantity on the left is greater

The quantity on the right is greater

B Both are equal

The relationship cannot be determined without further information 
What positive value for $\mathrm{k}$ would make the following the equations of a pair of parallel lines on the same coordinate axes?

$y=k x-2$ and $k y=9 x-7$

How many real roots does the polynomial $2 x^{5}+8 x-7$ have?
None
One
C Two
C Three
C Five

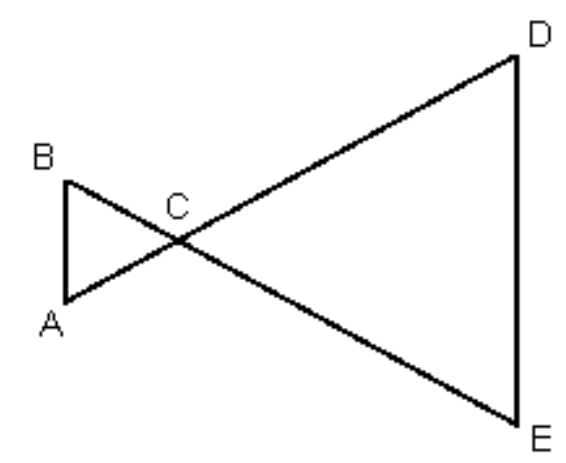

(Figure not to scale)

$\mathrm{AB}$ is parallel to $\mathrm{ED}$

$\mathrm{BCE}$ and $\mathrm{ACD}$ are line segments

\section{\begin{tabular}{l|l} 
length of $\mathrm{BC} \quad$ Length of $\mathrm{CA}$ \\
\hline
\end{tabular}}

C The quantity on the left is greater

C. The quantity on the right is greater

Both are equal

The relationship cannot be determined without further information

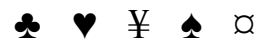

How many different 3-symbol arrangements of the symbols above are possible if the symbol a must be in the last position, and the symbol can be used in only one arrangement. The other symbols can be used more than once in an arrangement. 
$2^{30}+2^{30}+2^{30}+2^{30}=$

C $8^{120}$

C $8^{30}$

C $2^{32}$

C $2^{26}$

C $2^{30}$

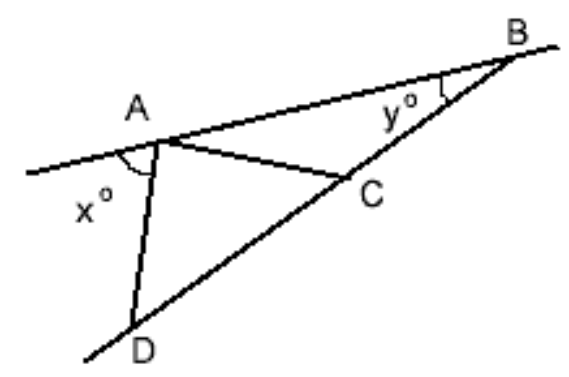

(figure not to scale)

In the figure above, $A D=A C=C B$.

If the value of $y$ is 28 , what is the value of $x$ ?

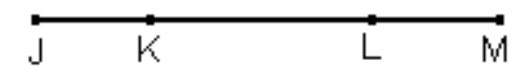

(figure not to scale)

$\mathrm{JL}=\mathrm{KM}$

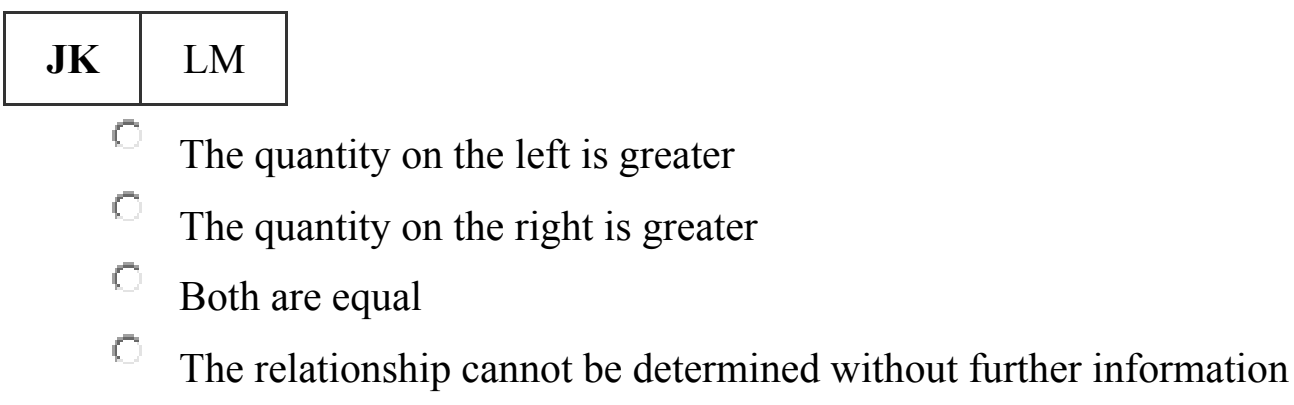




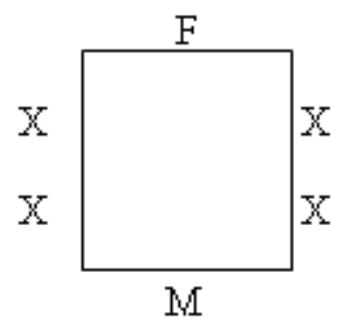

Family 1 comprising mother, father and son are to be seated at a table with family 2 comprising mother, father and daughter. The layout of the table is shown in the diagram. $F$ represents one of the fathers and $M$ represents one of the mothers. $X$ represents any family member. If a male family member must sit opposite a female of the other family, how many different seating plans are possible?

What is the units digit in the standard decimal expansion of the number $7^{25 ?}$

C 1
$6 \quad 3$
6
6
6

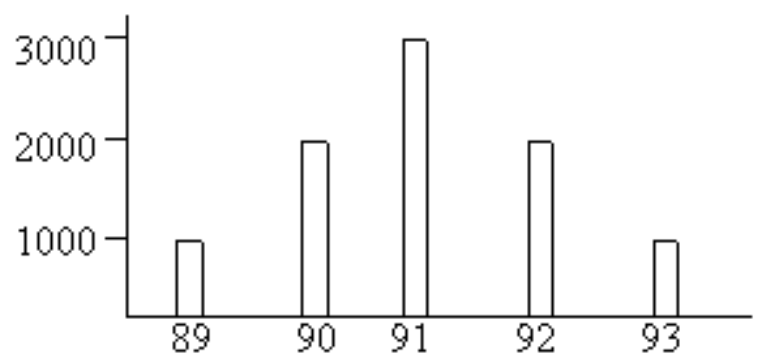

The graph shows the sales figures for a certain company in five consecutive years.

\section{Percentage increase in sales from 1989 to 1991}

Percentage fall in sales from 1991 to 1993

The quantity on the left is greater

The quantity on the right is greater

Both are equal

The relationship cannot be determined without further information

Given that the sum of the odd integers from 1 to 99 inclusive is 2500 , what is the sum of the even 
integers from 2 to 100 inclusive?

A straight fence is to be constructed from posts 6 inches wide and separated by lengths of chain 5 feet long. If a certain fence begins and ends with a post, which of the following could be the length of the fence in feet? (12 inches $=1$ foot).

Indicate ALL such answers.
$\ulcorner 17$
$\ulcorner 28$
Г 35
Г 39
Г 50 


\section{Appendix B}

Post-test Survey

1. On a scale from 0 to 10 , how hard would you say you tried on this test? (please circle one number)

$\begin{array}{lllllllllll}0 & 1 & 2 & 3 & 4 & 5 & 6 & 7 & 8 & 9 & 10\end{array}$

I didn't really try at all
I tried somewhat
I tried my hardest

2. On a scale from 0 to 10 , how would you rate your mood during the test? (please circle one number)

$\begin{array}{lllllllllll}0 & 1 & 2 & 3 & 4 & 5 & 6 & 7 & 8 & 9 & 10\end{array}$

Negative

Neutral

Positive

3. If you had to use one word to describe your mood during the testing portion of the session, what would that work be? (please write in your word)

4. Of the four words below, which one of these words is closest to the word you wrote in above to describe your mood during the test? (please check only one)

Unhappy $\_$Happy
Upset

4. On a scale from 0 to 10 , how would you rate your energy level during the test? (please circle one number)

$\begin{array}{lllllllllll}0 & 1 & 2 & 3 & 4 & 5 & 6 & 7 & 8 & 9 & 10\end{array}$

\section{Low Energy}

Moderate Energy

High Energy

4. If you had to use one word to describe your energy level the testing portion of the session, what would that work be? (please write in your word)

5. Of the four words below, which one of these words is closest to the word you wrote in above to describe your energy level during the test? (please check only one)

Tired

Alert

Relaxed Nervous 
Read each statement and circle the number that best describes how you were thinking during the test. There are no right or wrong answers. Do not spend too much time on any one statement.

\begin{tabular}{|c|c|c|c|c|c|c|c|c|c|c|c|}
\hline \multirow{2}{*}{$\begin{array}{l}\text { During the test I just took: } \\
\begin{array}{l}\text { 1. I asked myself how the test questions related to what I } \\
\text { already knew. }\end{array}\end{array}$} & \multirow{2}{*}{$\begin{array}{c}\begin{array}{c}\text { not at } \\
\text { all true }\end{array} \\
1\end{array}$} & \multicolumn{4}{|c|}{$\begin{array}{c}\text { somewhat } \\
\text { true }\end{array}$} & \multicolumn{3}{|c|}{$\begin{array}{l}\text { moderately } \\
\text { true }\end{array}$} & \multicolumn{2}{|c|}{$\begin{array}{c}\text { very much } \\
\text { true }\end{array}$} & \multirow{2}{*}{$\begin{array}{c}\begin{array}{c}\text { Not } \\
\text { sure }\end{array} \\
\text { NS }\end{array}$} \\
\hline & & \multicolumn{3}{|c|}{2} & & \multicolumn{3}{|c|}{3} & \multicolumn{2}{|r|}{4} & \\
\hline 2. I tried to determine what the test required. & 1 & \multicolumn{3}{|c|}{2} & \multicolumn{4}{|c|}{3} & & 4 & NS \\
\hline 3. I was aware of my ongoing thinking processes. & 1 & \multicolumn{3}{|c|}{2} & \multicolumn{4}{|c|}{3} & & 4 & NS \\
\hline $\begin{array}{l}\text { 4. I used multiple thinking techniques or strategies to } \\
\text { solve the test questions. }\end{array}$ & 1 & \multicolumn{3}{|c|}{2} & \multicolumn{4}{|c|}{3} & & 4 & NS \\
\hline 5. I checked my accuracy as I progressed through the test. & 1 & \multicolumn{3}{|c|}{2} & \multicolumn{4}{|c|}{3} & & 4 & NS \\
\hline $\begin{array}{l}\text { 6. I tried to understand the test questions before I } \\
\text { attempted to solve them. }\end{array}$ & 1 & \multicolumn{3}{|c|}{2} & \multicolumn{4}{|c|}{3} & & 4 & NS \\
\hline \multirow[b]{2}{*}{$\begin{array}{l}\text { 1. How well do test questions like these let you demonstrate } \\
\text { your knowledge of math? }\end{array}$} & \multicolumn{4}{|c|}{ Not At All } & \multicolumn{4}{|c|}{ Somewhat } & \multicolumn{3}{|c|}{ Very Well } \\
\hline & 0 & 1 & 2 & 3 & 4 & 5 & 6 & 7 & 8 & $\begin{array}{ll}9 & 10\end{array}$ & \\
\hline \multirow[b]{2}{*}{$\begin{array}{l}\text { 2. When you take a multiple-choice test like this in math, } \\
\text { how confident are you that you can correctly answer the } \\
\text { questions and do well on the test? }\end{array}$} & \multicolumn{2}{|c|}{$\begin{array}{l}\text { Not at all } \\
\text { Confident }\end{array}$} & & & \multicolumn{4}{|c|}{$\begin{array}{l}\text { Moderately } \\
\text { Confident }\end{array}$} & \multicolumn{3}{|c|}{$\begin{array}{c}\text { Very } \\
\text { Confident }\end{array}$} \\
\hline & 0 & 1 & 2 & 3 & 4 & 5 & 6 & 7 & 8 & $\begin{array}{ll}9 & 10\end{array}$ & \\
\hline \multicolumn{12}{|c|}{$\begin{array}{l}\text { 3. If we gave you feedback on how you did on this math test, which type of information would you prefer? } \\
\text { (please check only one) }\end{array}$} \\
\hline \multicolumn{12}{|c|}{ Feedback on the kinds of math knowledge and concepts you demonstrated mastery of on this test; } \\
\hline \multicolumn{12}{|c|}{ Feedback on how your test performance compared to other males and females of your age. } \\
\hline
\end{tabular}

Remember, give the answer which seems to best describe how you were thinking during the test. You can also check the last column, "not sure" (NS)

Below are some pairs of sentences. In the left hand column, read each pair and choose the one sentence that is most true for you. Then, in the right hand column, circle how true that sentence is for you using the scale that is given. 


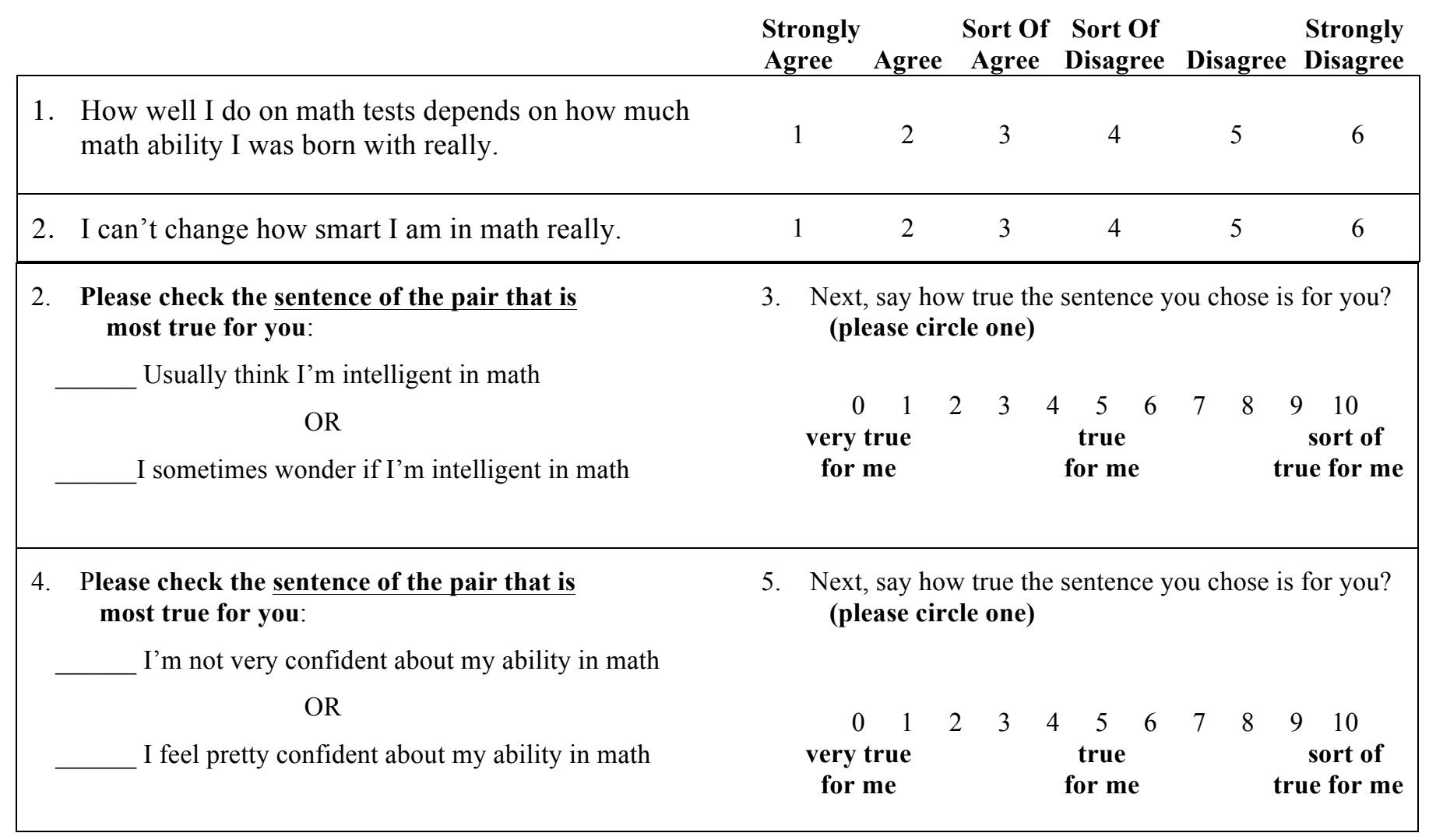

Please read each statement below and then circle the number that shows how much you agree or disagree with the statement. 